\title{
Eficiência energética de sistema de produção de suínos com tratamento dos resíduos em biodigestor
}

\author{
André R. Angonese ${ }^{1}$, Alessandro T. Campos ${ }^{2}$, Carlos E. Zacarkim ${ }^{1}$, Melissa S. Matsuo ${ }^{1}$ \& Francielly Cunha ${ }^{1}$
}

\begin{abstract}
RESUMO
Visando avaliar a sustentabilidade em um sistema de produção de suínos em terminação, realizou-se estudo de eficiência energética, através do acompanhamento de um lote de 120 dias, em sistema comercial, em Ouro Verde do Oeste, PR. Quantificou-se o coeficiente energético de cada componente envolvido no processo de produção e tratamento dos resíduos, por meio de biodigestor (entradas e saídas) e se determinaram as matrizes de consumo energético nas formas de ração, energia elétrica, mão-de-obra, equipamentos, instalações, produção de suínos vivos, produção de biofertilizante e de biogás. Os resultados indicaram que a atividade se enquadrou nas características de um agroecossistema industrial, altamente especializado, importando grande parte da energia consumida no processo de produção e destinado à exportação, com eficiência energética de $0,38\left(\mathrm{~J}_{\text {saída }} / \mathrm{J}_{\text {entrada }}\right)$. Da energia direta de entrada, $95,3 \%$ correspondem a ração e 4,6\% a leitões. Da energia de saída, 56,8\% se referem a suínos para abate, 30,1\% ao biofertilizante e $13 \%$ a biogás.
\end{abstract}

Palavras-chave: balanço de energia, biodigestão anaeróbia, construções rurais

\section{Energy efficiency of swine production system with biodigestor waste treatment}

\begin{abstract}
Aiming to assess the sustainability of a terminating swine production system, an energy efficiency study was carried out through a 120 days animal lot in a commercial system at Ouro Verde do Oeste, in the State of Paraná, Brazil. The energy rate of each compound involved in the production process and waste treatment using a biodigestor (input and output) was quantified. The matrixes of energy consumption were determined in the form of animal feeding, electrical energy, human labour, equipment, structures, alive swine production, biofertilizer production and biogas. The results indicated that the activity corresponded to an industrial agroecosystem, highly specialized, importing a great part of the energy consumed in the production process and applied to the exportation, with energy efficiency of $0.38\left(\mathrm{~J}_{\text {output }} / \mathrm{J}_{\text {input }}\right)$. In direct input energy, $95.3 \%$ correspond to animal feeding, $4.6 \%$ to the piglets, while in energy output $56.8 \%$ corresponded to the terminating swine, $30.1 \%$ to biofertilizer and $13 \%$ to biogas.
\end{abstract}

Key words: energy input and output, anaerobic digestion, farm structures

${ }^{1}$ Mestrando - CCA/UNIOESTE, Rua Pernambuco 1777, CEP 85960-000, Marechal Cândido Rondon-PR. Fone: (45) 3254 3216. E-mail: aangonese@uol.com.br; carloseduardo_zacarkim@yahoo.com.br; melissamatsuo@yahoo.com.br; franciellyc@bol.com

${ }_{2}^{2}$ CCA/GPEA/UNIOESTE, Rua Pernambuco 1777, CEP 85960-000, Marechal Cândido Rondon, PR. Fone (45) 3254 3216. E-mail: atcampos@unioeste.br 


\section{INTRODUÇÃO}

A preocupação com a elevação do consumo de combustíveis fósseis na atividade agrícola, tem estimulado o desenvolvimento de técnicas para a quantificação das entradas e saídas de energia na agricultura, possibilitando o cálculo do balanço energético (Quesada et al., 1987).

A expansão da atividade suinícola no País e o incremento tecnológico nos sistemas de produção, têm resultado em aumento na geração de dejetos os quais são, muitas vezes, lançados em rios e mananciais. Devido à adoção de sistemas confinados de produção de suínos, grandes quantidades de dejetos são produzidas.

Valores compreendidos entre 5,7 e 7,6 L por suíno por dia são constatados para suínos em faixa de peso de 57 a $97 \mathrm{~kg}$; este volume de dejetos produzidos pode situar-se entre $10 \mathrm{e}$ $8 \%$ da massa do animal (Sevrin-Reyssac et al., 1995).

Dejetos gerados de suinoculturas apresentam elevado potencial de poluição mas, por outro lado, podem ser uma alternativa energética como fertilizante e, também, como alimento para outras espécies (Oliveira, 1993). Quando bem escolhido e conduzido, o manejo adotado permite o aproveitamento integral dos dejetos, dentro das condições estabelecidas em cada propriedade.

O balanço de energia nos sistemas agrícolas vem sendo estudado por diversos pesquisadores (Campos, 2001; Beber, 1989; Carvalho \& Lucas Jr., 2001; Santos et al., 1994; Oliveira, 1993), e se baseia no princípio físico de conservação de energia, também conhecido como primeiro princípio da termodinâmica, ou seja, a variação de energia em um processo pode ser explicada pelo balanço de energia, isto é, entradas, saídas e variação da energia interna.

A análise de agroecossistemas sob a ótica de seus fluxos energéticos pode ser um instrumento para avaliação de balanço energético em sistemas de produção de suínos, e, segundo Mello (1986), está em fase de aperfeiçoamento.

Os balanços energéticos são indicadores relacionadores de energia e constituem promissora abordagem técnica para se avaliar e investigar problemas relacionados à sustentabilidade e eficiência de sistemas agrícolas (Giampietro et al., 1992).

Sistemas biointegrados podem maximizar o aproveitamento energético dos dejetos gerados pela suinocultura, dentro do próprio agroecossistema, reduzindo a contaminação exterior dos recursos naturais.

Com este trabalho, objetivou-se avaliar os fluxos de energia em um sistema de produção de suínos em terminação, o balanço energético relativo à produção dos suínos e a reciclagem dos resíduos gerados no sistema para utilização como fertilizantes orgânicos.

\section{MATERIAL E MÉTODOS}

O estudo foi desenvolvido na Fazenda Vale dos Ipês, que possui uma unidade de terminação de suínos (UT), com capacidade instalada para 650 animais, localizada no município de Ouro Verde do Oeste, no Oeste do estado do Paraná, situada a uma latitude de $24^{\circ} 46^{\prime} 40^{\prime \prime}$ Sul e longitude de $54^{\circ} 01^{\prime} 10^{\prime}$ Oeste, com altitude média de $300 \mathrm{~m}$ (Brasil, 1980). O clima da região é do tipo Cfa (Köppen), subtropical, úmido, mesotérmico, com precipitação média anual de 1.600 a $1.700 \mathrm{~mm}$.

A unidade de produção consta com um galpão de alvenaria com $874 \mathrm{~m}^{2}$, coberto com telhas cerâmicas sobre estrutura de madeira e beiral de $0,90 \mathrm{~m}$, que conduz as águas pluviais para o exterior.

Os dejetos são encaminhados para canaletas laterais, que não recebem as águas da chuva. Para redução do volume de dejetos, a limpeza é feita através de raspagem a seco e os bebedouros são do tipo "chupeta".

O galpão é dividido em 30 baias cada um, com capacidade para 22 animais.

O sistema foi delimitado pelas atividades relativas ao recebimento, trato e carregamento dos suínos em sistema de terminação $(22$ a $110 \mathrm{~kg}$ ) e o tratamento dos resíduos gerados, incluindo-se todos os processos, gastos e gerações energéticas embutidas na atividade, o qual pode ser visualizado no esquema discriminado abaixo:

SISTEMA DE PRODUÇÃO DE SUÍNOS

- Infra-estrutura para confinamento dos animais

- Instalações para confinamento

- Suínos em engorda

- Silo para depósito ração

- Caixa de água

- Infra-estrutura para tratamento dos resíduos

- Instalações compostagem animais mortos

- Biodigestor

- Decantador

- Depósito biofertilizante

- Tanque de algas

O tempo de acompanhamento do sistema foi de um lote ou ciclo, ou seja, desde a chegada dos leitões até a saída para o abate, correspondendo ao período de 120 dias.

A eficiência energética $(\eta)$ foi obtida seguindo-se a equação definida por Quesada et al. (1991):

$$
\eta=\frac{\sum \mathrm{E}_{\text {saida }}}{\sum \mathrm{E}_{\text {Consumo }}}
$$

onde:

$$
\begin{aligned}
\sum \mathrm{E}_{\text {saída }} & =\sum\left(\mathrm{E}_{\text {Dsaída }}+\mathrm{E}_{\text {Isaída }}\right) \\
\sum \mathrm{E}_{\text {consumo }}= & \sum\left(\mathrm{E}_{\text {Dconsumo }}+\mathrm{E}_{\text {Iconsumo }}\right) \\
\mathrm{E}_{\mathrm{D}}- & \text { estimativa de energia direta } \\
\mathrm{E}_{\mathrm{I}}- & \text { estimativa de energia indireta } \\
\mathrm{E}_{\text {saída }}- & \text { estimativa de energia que sai no processo de } \\
& \text { produção (em forma de produto }) \\
\mathrm{E}_{\text {consumo }}- & \text { estimativa de energia consumida no processo de } \\
& \text { produção }
\end{aligned}
$$

Considerou-se energia útil aquela disponível: a) suíno para abate; b) na forma de biofertilizante, c) na forma de nutrientes (a serem utilizados na produção de algas e como adubo orgânico) e d) aquela disponível pela geração de metano.

Como energia direta utilizou-se aquela relativa à ração, a elétrica, dos leitões e dos insumos diretamente consumidos 
no processo de produção e, como energia indireta, foi considerada a empregada na fabricação de equipamentos, nas construções e instalações, nos sistemas de irrigação e entre outros necessários à produção.

Para obtenção dos coeficientes energéticos fez-se a transformação em unidades calóricas dos componentes envolvidos no processo de produção de suínos em sistema de terminação, seguindo-se coeficientes energéticos estabelecidos por diversos autores os quais são visualizados nas Tabelas 1 e 2 .

Tabela 1. Componentes das entradas energéticas da produção agropecuária e seus respectivos coeficientes energéticos, de acordo com as fontes

\begin{tabular}{|c|c|c|c|}
\hline Componente de entrada & $\begin{array}{l}\text { Coeficiente } \\
\text { energético }\end{array}$ & Unidades & $\begin{array}{l}\text { Vida útil } \\
\text { (anos) }\end{array}$ \\
\hline Trabalho humano ${ }^{1}$ & 4,39 & MJ homem $\mathrm{h}^{-1}$ & \\
\hline Equipamentos ${ }^{1}$ & 83,71 & MJ kg-1 & 30 \\
\hline Eletricidade $^{2}$ & 13,11 & MJ kWh-1 & \\
\hline Aço $^{1}$ & 62,78 & $\mathrm{MJ} \mathrm{kg}^{-1}$ & 20 \\
\hline $\mathrm{PVC}^{1}$ & 119,99 & MJ kg-1 & 40 \\
\hline Madeira² $^{2}$ & 13,81 & MJ kg-1 & \\
\hline Fundação/concreto ${ }^{3}$ & 641,64 & $\mathrm{MJ} \mathrm{m}^{-3}$ & \\
\hline Piso de concreto ${ }^{3}$ & 86,33 & $M J m^{-2}$ & \\
\hline Plásticos ${ }^{4}$ & 130,04 & MJ kg-1 & \\
\hline Fio elétrico ${ }^{4}$ & 45,02 & MJ kg-1 & \\
\hline Telha cerâmica ${ }^{5}$ & 3,60 & MJ kg-1 & \\
\hline Parede de tijolos ${ }^{3}$ & $1.208,17$ & $\mathrm{MJ} \mathrm{m}^{2}$ & \\
\hline Ração $0^{6}$ & 17,00 & MJ kg-1 & \\
\hline
\end{tabular}

Tabela 2. Componentes das saídas energéticas da produção agropecuária e seus componentes energéticos, de acordo com as fontes

\begin{tabular}{lcc}
\hline Componente de entrada & Coeficiente energético & Fonte \\
Gás metano & $55,25 \mathrm{MJ} \mathrm{L}^{-1}$ & Brasil (2001) \\
Suíno & $9,21 \mathrm{MJ} \mathrm{kg}^{-1}$ & Comitre (1995) \\
$\mathrm{N}$ & $73 \mathrm{MJ} \mathrm{kg}^{-1}$ & Pellizzi (1992) \\
$\mathrm{P}_{2} \mathrm{O}_{5}$ & $13 \mathrm{MJ} \mathrm{kg}^{-1}$ & Pellizzi (1992) \\
$\mathrm{K}_{2} \mathrm{O}$ & $9 \mathrm{MJ} \mathrm{kg}^{-1}$ & Pellizzi (1992) \\
\hline
\end{tabular}

Para o cálculo mais acurado do balanço energético das instalações rurais, fez-se opção pela composição energética mais detalhada, aplicando-se os valores de composição energética dos materiais utilizados em construções e desenvolvidos pelo CETEC, conforme Fernandes \& Souza (1982) e Campos et al. (2003).

\section{Instalações e sistema de tratamento de dejetos}

Para o depósito da ração utilizou-se um silo pré-fabricado em aço galvanizado, com capacidade de 12 t. O depósito de água é uma caixa fabricada em aço carbono com capacidade para $10.000 \mathrm{~L}$.

A condução dos dejetos ao biodigestor é feita por gravidade, através de tubos de PVC de $150 \mathrm{~mm}$, com o propósito de evitar a entrada da água da chuva e do pátio. O biodigestor é formado por dois tanques cilíndricos (usados em postos de combustível) de 15.000 L cada um, construídos em aço carbono, com entrada e saída dispostas de forma a manter o fluxo contínuo dos resíduos. O tempo de retenção hidráulica (TRH) foi de 10 dias.

O biodigestor possui tubulação independente para captação do gás nele gerado, sendo armazenado em balões de PVC com capacidade para $20 \mathrm{~m}^{3}$. O medidor utilizado para a medição da produção de biogás foi da Indústria LAO modelo $\mathrm{G} 1$, com precisão de $0,2 \mathrm{dm}^{3}$.

Após passar pelo biodigestor, o efluente é conduzido ao tanque de sedimentação, construído em alvenaria, de formato retangular, de profundidade crescente no sentido da saída do efluente, com capacidade para $30 \mathrm{~m}^{3}$; dispõe de duas saídas, uma de fundo, para retirada do lodo (biofertilizante) e outra superior, para saída da fração mais líquida que tem, como destino, o tanque de algas.

Utilizou-se no presente trabalho, a metodologia desenvolvida por Doering III et al. (1977) e empregada por diversos autores (Beber, 1989; Comitre, 1995; Campos et al., 2003; Carvalho \& Lucas Jr., 2001), a qual consiste na aplicação de um método baseado na depreciação energética, à semelhança da depreciação econômica e com base na massa das máquinas, consiste em depreciá-los durante sua vida útil.

$\mathrm{O}$ coeficiente energético do metano foi de $55,25 \mathrm{MJ} \mathrm{L}^{-1}$ (Brasil, 2001). A composição mínima de metano no biogás foi adotada como 79\% (Toledo \& Lucas Jr., 1996)

Para obtenção dos teores de $\mathrm{N}, \mathrm{P}_{2} \mathrm{O}_{5}$ e $\mathrm{K}_{2} \mathrm{O}$, efetuaram-se análises no Instituto de Tecnologia do Paraná (TECPAR) de acordo com os métodos analíticos estabelecidos pela APHA (1991).

\section{RESULTADOS E DISCUSSÃO}

\section{Consumo de energia (inputs)}

Da energia empregada no sistema, o maior consumo observado foi da categoria direta, com $99,43 \%$ do total, sendo $0,57 \%$ para a indireta. Pela Tabela 3 percebe-se preponderância da energia direta, através da ração $(95,28 \%)$ utilizada como alimento dos animais. A ração é produzida a partir de milho e soja, tratando-se de recurso renovável. Carvalho \& Lucas Jr. (2001), estudando o balanço de energia com vistas à produção industrial e à de ovos, respectivamente apontaram a ração para as

Tabela 3. Consumo de energia indireta e direta para a produção de suínos no ciclo período de 120 dias

\begin{tabular}{|lrr}
\hline Entradas de energia & \multicolumn{1}{c}{ CE (MJ) } & \multicolumn{1}{c}{$\%$} \\
\hline Energia indireta total & $16.638,03$ & 0,57 \\
\hline Estrutura do galpão & $9.151,14$ & 55,00 \\
\hline Silo de ração & 890,78 & 5,35 \\
\hline Biodigestor & $3.785,80$ & 22,75 \\
\hline Caixa d'água & $1.002,12$ & 6,02 \\
\hline Decantador e tanque algas & $1.808,20$ & 10,87 \\
Energia direta total & $2.890 .311,00$ & 99,43 \\
\hline Ração & $2.754 .000,00$ & 95,28 \\
\hline Leitões & $131.703,00$ & 4,56 \\
\hline Trabalho humano & $3.168,00$ & 0,11 \\
\hline Eletricidade & $1.440,00$ & 0,05 \\
\hline Total Entradas & $2.906 .949,03$ & 100,00 \\
\hline
\end{tabular}


aves como o componente de maior aporte de energia no processo $(84,70 \%$ do total da energia empregada).

O total de energia indireta gasta por ciclo de produção, foi $16.638,03 \mathrm{MJ}$, sendo que a estrutura do galpão representa $55 \%(9.151,14 \mathrm{MJ})$, seguido pelo biodigestor, com $22,8 \%$ $(3.785,8 \mathrm{MJ})$ do total de energia indireta. A Tabela 3 permite uma visualização melhor do consumo de energia indireta de cada equipamento ou instalação depreciado dentro do período estudado.

A Tabela 4 mostra a quantidade de ração por tamanho, número de suínos e ração total consumida para o lote.

Tabela 4. Quantidade de ração consumida para o lote de suínos de 650 animais em 120 dias de trato

\begin{tabular}{|c|c|c|c|c|}
\hline Data início & Dias & $\mathrm{kg} \mathrm{d}^{-1}$ suíno-1 $^{-1}$ & $\begin{array}{l}\text { Consumo total } \\
\text { acumulado }(\mathrm{kg})\end{array}$ & $\begin{array}{c}\text { Consumo } \\
\mathrm{kg} \mathrm{d}^{-1}\end{array}$ \\
\hline 21/9/2004 & 1 a 7 & 1,00 & $4.550,0$ & 650,0 \\
\hline 28/9/2004 & 8 a 14 & 1,20 & $10.010,0$ & 780,0 \\
\hline $5 / 10 / 2004$ & 15 a 21 & 1,30 & $15.925,0$ & 845,0 \\
\hline $12 / 10 / 2004$ & 22 a 28 & 1,50 & $22.750,0$ & 975,0 \\
\hline 19/10/2004 & 29 a 35 & 1,70 & $30.485,0$ & $1.105,0$ \\
\hline 26/10/2004 & 36 a 42 & 1,75 & $38.447,5$ & $1.137,5$ \\
\hline 02/11/2004 & 43 a 49 & 2,00 & $47.547,5$ & $1.300,0$ \\
\hline 09/11/2004 & 50 a 56 & 2,20 & $57.557,5$ & $1.430,0$ \\
\hline $16 / 11 / 2004$ & 57 a 63 & 2,30 & $68.022,5$ & $1.495,0$ \\
\hline 23/11/2004 & 64 a 70 & 2,40 & $78.942,5$ & $1.560,0$ \\
\hline 30/11/2004 & 71 a 77 & 2,40 & $89.862,5$ & $1.560,0$ \\
\hline 07/12/2004 & 78 a 84 & 2,50 & $101.237,5$ & $1.625,0$ \\
\hline $14 / 12 / 2004$ & 85 a 91 & 2,60 & $113.067,5$ & $1.690,0$ \\
\hline 21/12/2004 & 92 a 98 & 2,60 & $124.897,5$ & $1.690,0$ \\
\hline 28/12/2004 & 99 a 105 & 2,70 & $137.182,5$ & $1.755,0$ \\
\hline 04/01/2005 & 106 a 112 & 2,70 & $149.467,5$ & $1.755,0$ \\
\hline 11/01/2005 & 113 а 120 & 2,80 & $164.027,5$ & $1.820,0$ \\
\hline
\end{tabular}

Itens como mão-de-obra, eletricidade, leitões e energia indireta utilizada no sistema, de uso essencial na produção, apresentaram valores energéticos baixíssimos na composição de consumo energético.

Dentre os resultados obtidos referentes ao cálculo da energia indireta utilizada no sistema, o galpão da suinocultura foi o item mais representativo.
Comitre (1995) salienta que, além de ser difícil determinar um padrão médio de edificações rurais, encontrar coeficientes energéticos compatíveis com a realidade rural brasileira representa uma tarefa extremamente difícil.

Com base na conclusão de Comitre, determinou-se o coeficiente energético (CE) do galpão através dos diferentes componentes empregados na construção das instalações da suinocultura, conforme se observa na Tabela 5 .

Esta instalação consumiu o total de $835.880 \mathrm{MJ}$ em sua construção; considerando-se a área útil total de galpão destinada ao confinamento dos suínos $\left(874,32 \mathrm{~m}^{2}\right)$, o índice energético determinado foi de $956,03 \mathrm{MJ} \mathrm{m}^{-2}$. Este valor pode ser considerado bem abaixo daqueles apresentados por Doering III (1980) de $1.711,43 \mathrm{MJ} \mathrm{m}^{-2}$ para construções de serviço e $6.260,23 \mathrm{MJ} \mathrm{m}^{-2}$ para residência e bem acima do valor indicado por Pimentel (1980) para instalações de madeira (58,91 $\left.\mathrm{MJ} \mathrm{m}^{-2}\right)$; já Campos et al. (2003), analisando uma edificação em alvenaria com estrutura aéreo-portante em concreto armado para armazenamento de feno, obtiveram o coeficiente energético de $622,23 \mathrm{MJ} \mathrm{m}^{-2}$.

\section{Síntese e consolidação do balanço de energia para o ciclo de produção de suínos em sistema de terminação}

Analisaram-se os diversos processos e operações envolvidos no sistema de produção de suínos, desde a chegada dos leitões, com peso médio de $22 \mathrm{~kg}$, até o período de abate, com média de $110 \mathrm{~kg}$ por suíno.

Os resultados das análises efetuadas no biofertilizante podem ser observados na Tabela 6 .

Tabela 6. Características do biofertilizante em macro nutrientes

\begin{tabular}{|c|c|c|}
\hline \multirow[b]{2}{*}{ Parâmetros } & \multicolumn{2}{|c|}{ Concentração média } \\
\hline & Biofertilizante líquido & $\begin{array}{l}\text { Biofertilizante } \\
\text { concentrado }\end{array}$ \\
\hline Nitrogênio total $\left(\mathrm{g} 100 \mathrm{~g}^{-1}\right)$ & 0,0067 & 0,130 \\
\hline Fósforo $\left(\mathrm{P}_{2} \mathrm{O}_{5}\right)\left(\mathrm{g} 100 \mathrm{~g}^{-1}\right)$ & 0,0213 & 0,070 \\
\hline Potássio $\left(\mathrm{K}_{2} \mathrm{O}\right)\left(\mathrm{g} 100 \mathrm{~g}^{-1}\right)$ & 0,0014 & 0,050 \\
\hline
\end{tabular}

A Tabela 7 apresenta, condensadamente, todas as entradas de energia, nas formas direta e indireta, e o balanço

Tabela 5. Consumo de energia (CE) na construção do galpão de suinocultura

\begin{tabular}{llcrrr}
\hline & Espécie/Material & Unidade & Quantidade & CE (kJ Ud-1) & CE (MJ) \\
Concreto/piso & Concreto/pré-moldados & $\mathrm{m}^{3}$ & 4,33 & $614.637,97$ & $2.661,38$ \\
& Concreto/fundação & $\mathrm{m}^{3}$ & 6,50 & $614.637,97$ & $3.995,15$ \\
& Piso & $\mathrm{m}^{2}$ & 874,32 & $86.327,20$ & $75.477,60$ \\
\multirow{2}{*}{ Madeira } & Ripas & $\mathrm{m}^{3}$ & 3,86 & $8.287 .290,00$ & $32.005,51$ \\
& Caibro & $\mathrm{m}^{3}$ & 8,33 & $8.287 .290,00$ & $69.033,13$ \\
& Tabuas & $\mathrm{m}^{3}$ & 5,75 & $8.287 .290,00$ & $47.651,92$ \\
Parede & Terças & $\mathrm{m}^{3}$ & 12,90 & $8.287 .290,00$ & $106.906,04$ \\
Cobertura & Parede & $\mathrm{m}^{2}$ & 231,00 & $1.208 .171,61$ & $279.087,64$ \\
Tubulação & Telha de cerâmica & $\mathrm{m}^{2}$ & 1074,00 & $166.350,00$ & $178.659,90$ \\
Instalação elétrica & PVC & $\mathrm{kg}$ & 170,00 & $119.985,73$ & $20.397,57$ \\
Cortina plástica & Fio elétrico & $\mathrm{kg}$ & 5,00 & $45.000,00$ & 225,00 \\
Tela de arame & Lona & $\mathrm{kg}$ & 120,00 & $130.000,00$ & $15.600,00$ \\
Somatório das estruturas & Tela arame & $\mathrm{kg}$ & 100,00 & $41.800,00$ & $4.180,00$ \\
\hline
\end{tabular}


energético consolidado, considerando-se os valores médios utilizados para o cálculo.

Tabela7. Eficiência energética dos componentes energéticos da relação Consumo/Produção para o ciclo produtivo no sistema de terminação de suínos

\begin{tabular}{lr}
\hline Fontes de consumo/saídas & CE (MJ) \\
Consumo & \\
Energia indireta total & $16.638,03$ \\
Energia direta total & $2.890 .311,00$ \\
Total Entradas & $2.906 .949,03$ \\
Saídas "Outputs" & \\
Biofertilizante & $335.186,10$ \\
Suínos $(\mathrm{kg})$ & $632.775,00$ \\
Biogás $\left(\mathrm{m}^{3}\right)$ & $145.200,00$ \\
Total Saídas & $1.113 .161,10$ \\
Eficiência Energética & 0,38 \\
\hline
\end{tabular}

No item saída de energia "outputs", o componente mais significativo foi o suíno, com $56,8 \%$ do total de energia produzida; ao se verificar, ainda, os valores de saída de energia, observa-se que o componente biofertilizante assume valores importantes, com $30,2 \%$ do total da energia. Carvalho \& Lucas Jr. (2001), estudando a produção industrial de ovos, notaram valores significativos do componente dejetos, especialmente nas fases de recria, com $83 \%$ do valor total de energia outputs.

A produção média diária de biogás foi de $31,5 \mathrm{~m}^{3}$, equivalente a $0,63 \mathrm{~m}^{3} \mathrm{~m}^{-3}$ do biodigestor. Zhang et al. (1990) em estudo realizado com dejetos de suínos, encontraram valor de $0,57 \mathrm{~m}^{3} \mathrm{~m}^{-3}$ de biodigestor.

O biogás foi outro relevante componente representando, em média, 13\% dos valores totais de energia (Figura 1), destacando-se a importância da energia da biomassa dos dejetos, corroborando com as afirmações dos autores Beber (1989), Goldemberg (1998) e Carvalho \& Lucas Jr. (2001).

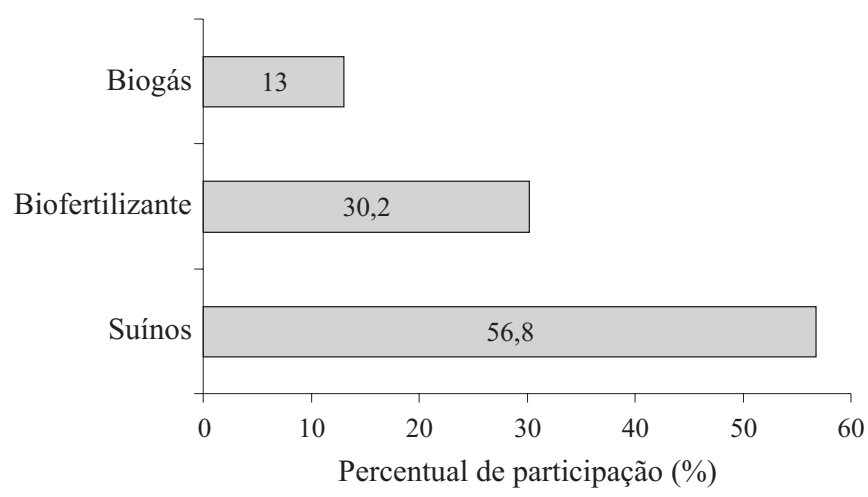

$\overline{\text { Figura 1. Participação percentual dos coeficientes energéticos (MJ) dos itens }}$ resultantes do sistema produtivo (outputs)

Conforme a Tabela 7, a eficiência energética do sistema de produção de suínos em terminação, foi de 0,38. Quesada et al. (1987) obtiveram uma eficiência energética de 0,06, avaliando um sistema de produção de suínos no Rio Gran- de do Sul, mas se percebe que o estudo não apresenta sistema de tratamento com obtenção de biogás e os autores não consideraram a utilização dos fertilizantes. A possibilidade de integração de atividades dentro de uma mesma propriedade e aproveitamento total dos resíduos, proporciona maior sustentabilidade, em termos de eficiência energética e ambiental.

Outro ponto importante realce, é o avanço da tecnologia de produção de ração e o melhoramento genético dos animais, resultando numa conversão alimentar melhor, possibilitando desta forma, melhoria no índice energético.

Beber (1989) afirma que valores de eficiência energética ( $\eta$ ) menores que 1 , demonstram que o sistema importa, praticamente, toda a energia consumida no processo produtivo.

Uma das possíveis medidas a serem tomadas visando à sustentabilidade do sistema, seria a possibilidade da produção, in loco, da alimentação dos animais que, para o atual modelo de criação, se depara com problemas técnicos relativos ao processo de produção das rações.

\section{CONCLUSÕES}

1. O componente energético ração é o maior custo energético no sistema de produção de suínos em terminação, correspondendo a $95,3 \%$ do total da energia direta.

2. Nas saídas de energia do sistema, o componente energético dos suínos para abate corresponde a 56,8\%.

3. O sistema se enquadrou nas características de um agroecossistema industrial, importando a maior parte da energia consumida no processo produtivo e exportando mais de $56 \%$ da produção, na forma de suínos para abate enquanto o restante é utilizado na forma de adubo, na propriedade.

4. A produção de dejetos tem valor energético considerável (em torno de $30 \%$ da energia de saída total do sistema), no sentido de sua efetiva utilização no próprio sistema, por meio da renovação de energia, reduzindo o impacto ambiental e minimizando a importação de energia.

\section{LITERATURA CITADA}

APHA-AWWA-WEF. Standard methods for the examination of water and wastewater, 17 th ed. Washington, D. C.: APHA, 1991. 1144p.

Beber, J. A. C. Eficiência energética e processos de produção em pequenas propriedades rurais. Santa Maria; UFSM, 1989, 295p. Dissertação Mestrado

Brasil. Ministério do Exército. Cartas do exército. Brasília: Departamento de Engenharia e Comunicações, 1980. Folha SG.21X-B-VI-4-MI-2816-4, Escala 1.

Brasil. Ministério de Minas e Energia. Balanço energético nacional. Brasília, 2001. 154p.

Campos, A. T.; Novaes, L. P.; Campos, A. T.; Ferreira, W. A.; Bueno, O. C. Balanço energético na produção de silagem de milho em cultivos de verão e inverno com irrigação. In: Congresso Argentino de Engeneria Agrícola, 2000, Buenos Aires. Anais... Buenos Aires: Editorial Facultad de Agronomia, 2000. 
Campos, A. T. Balanço energético relativo à produção de feno de "coast-cross" e alfafa em sistema intensivo de produção de leite. Botucatu; UNESP/FCA, 236p., 2001. Tese Doutorado

Campos, A. T.; Saglietti, J. R. C.; Campos, A. T.; Bueno, O. C.; Gasparino, E.; Klosowski, E. S. Custo energético de construção de uma instalação para armazenagem de feno. Ciência Rural. Santa Maria, v.33, n.4, p.667-672, 2003.

Carvalho, S. M. R.; Lucas Jr., F. Balanço energético e potencial de produção de biogás em granja de postura comercial na região de Marília, SP. Energia na Agricultura. Botucatu, v.16, n.1, p. 40-61, 2001.

Comitre, V. A questão energética e o padrão tecnológico da agricultura brasileira. Informações Econômicas, São Paulo, v.25, n.12, p.29-35, 1995.

Doering III, O. C. Accouting for energy in farm machinery and buildings. In: Pimentel, D. (ed.), Handbook of energy utilization in agriculture. Boca Raton: CRC Press, 1980. p.9-14.

Doering III, O. C.; Considine, T. J.; Harling, C. E. Accounting for tillage equipment and other machinery in agricultural energy analysis. Indiana, West Lafayette: Purdue University, 1977. 4p. Agricultural Experiment Station NSF/RA - 770128

Fernandes, M. P.; Souza, A. T. M. Balanço energético - o consumo de energia na construção civil. Revista Brasileira Tecnologia, Brasília, v.13, n.3, p.22-36, 1982.

Giampietro, M.; Cerretelli, G.; Pimentel, D. Energy analysis of agricultural ecosystem management: human return and sustainability. Agriculture, Ecosystems and Environment, Amsterdam, v.38, n.3, p.219-244, 1992.

Goldemberg, J. Energia, meio ambiente \& desenvolvimento. São Paulo: Editora da USP, 1998. 234p.

Mello, R. Análise energética de agroecossistemas: o caso de Santa Catarina. Florianópolis: UFSC,1986. 139p. Dissertação Mestrado
Oetting, L. L. Avaliação de diferentes marcadores para a determinação da digestibilidade e taxa de passagem do alimento em suínos. Piracicaba: USP, 2002.59p.Dissertação Mestrado

Oliveira, P. A. V. Manual de manejo e utilização dos dejetos de suínos. EMBRAPA Centro Nacional Suínos e Aves /, Concórdia, , , 1993. p.1-188,Circular Técnica. n.27

Pellizzi, G. Use of energy and labour in Italian agriculture. Journal of Agricultural Engineering Research, Silsoe, v.52, n.2, p.111-119, 1992.

Pimentel, D. Handbook of energy utilization in agriculture. Boca Raton: CRC Press, 1980, 475p.

Quesada, G. M.; Beber, J. A. C.; Souza, S. P. Balanços energéticos uma proposta metodológica para o Rio Grande do Sul. Ciência e Cultura. São Paulo, v.39, n.1, p.20-28, 1987.

Quesada, G. M.; Pereira Filho, O. P.; Beber, J. A. C.; Neumann, P. S. Energia, organização social e tecnologia. Ciência e Ambiente, Santa Maria, v. , n.2, p.13-29, 1991.

Santos, H. P.; Fancelli, A. L.; Reis. Balanço energético de sistemas de rotação de culturas para trigo, em plantio direto. Pesquisa Agropecuária Brasileira, Brasília, v.29, n.7, p. 10671073, 1994.

Sevrin-Reyssac, J.; La Noüe, J.; Proulx, D. Le recyclage du lisier de porc par lagunage. Paris: Lavoisier. 118p. 1995. Éditions Technique \& Documentation

Toledo, A. A. G. F.; Lucas Jr., J. Produção de biogás a partir de águas residuárias de pocilgas utilizando reatores UASB sob quatro tempos de retenção hidráulica. Energia na Agricultura, Botucatu, v.12, n.12, p.49-55, 1996.

Zhang, R. H.; North, J. R.; Day, D. L. Operation of a field scale anaerobic digester on a swine farm. Applied Engineering in Agriculture, St. Joseph, v.6, n.6, p.771-776, 1990. 